\title{
Stock Return Variations: The Validity of Systemic Risk, Size and Valuation as Explanatory Variables in the Lebanese Stock Market
}

\author{
Jamil Chaya $^{1}$, Jamil A. Hammoud ${ }^{1} \&$ Wael A. Saleh ${ }^{1}$ \\ ${ }^{1}$ College of Business Administration, Rafik Hariri University, Lebanon \\ Correspondance: Jamil Chaya, Assistant Professor, College of Business Administration, Rafik Hariri University, \\ Mechref, Lebanon. E-mail: chayajk@ rhu.edu.lb
}

Received: October 20, 2020

Accepted: December 10, 2020

Online Published: January 20, 2021

doi:10.5430/ijfr.v12n3p135

URL: https://doi.org/10.5430/ijfr.v12n3p135

\begin{abstract}
Understanding stock return variations and accounting for their drivers help academics and practitioners estimate expected returns and gauge risk exposures, thereby optimizing investment strategies. This paper seeks to study the effect of systemic risk, size and valuation on stock return, in the Lebanese stock market. The research design and methodology are the Fama French Factor Model (FFFM) as developed by Fama and French in their seminal work of 1993. The research demonstrates validity of the three variables in question, and that is consistent with results obtained for global equity markets. However, the results exhibit a negative market risk premium with respect to US T-bills, and a high level of factor inter-correlation for the period in question.
\end{abstract}

Keywords: stock return, stock markets, Lebanon, Beirut Stock Exchange, investment, CAPM, FFFM

JEL Classification Code: G15

\section{Introduction}

The Fama French Factor Model (FFFM) and other Arbitrage Pricing Theory (APT) derivative models are utilized by academics and finance practitioners to estimate expected returns of securities and portfolios, and to gauge risk exposures to markets, size, and valuation. An analyst can use stock market data to identify over/under exposure to risk factors and consequently construct an optimally designed portfolio that meets investment objectives.

Given the significance of systemic risk, size and valuation as explanatory variables of cross-sectional average stock return variations, in American stock markets, obtained in FFFM, it was interesting to see if these same factors are also significant in the context of a small and emergent economy stock market, such as the Beirut Stock Exchange. Investors in the Lebanese stock market can always use the Fama French Factors (FFF) as derived from global emerging equity markets. Yet that will depend on the level of exposure to global markets, at the expense of country specific conditions, which may in fact taint performance.

\section{Development of the FFFM}

In 1952, the first portfolio selection theory or the "Modern Portfolio Theory" was established by Harry Markowitz (1952), to have later on a great impact in portfolio management. The idea behind this theory is that one can maximize his returns and minimize risk by creating well-diversified portfolio of securities. Indeed, Markowitz introduced the Expected Return-Variance Maxim, or E-V Maxim which stipulates that investors should select the portfolio which yields the highest expected return, for a specific level of risk. This advice is based on the proposition that rational investors should choose portfolios located on the efficient frontier, which contains at least one portfolio that exhibits a higher expected return and less risk than the least risky of its components.

Subsequently, William Sharpe (1964) and John Lintner (1965) introduced the Capital Asset Pricing Model (CAPM), which allows investors to measure systemic risk and demonstrated a linear relationship between systemic risk and return (Fama \& French, 2004). The CAPM used the notion of a market portfolio to measure an equity market premium capable of gauging asset/portfolio exposure to overall market risk. The resulting " $\beta$ ", market risk coefficient, has become a staple in investment practice for portfolio construction and risk evaluation. Accordingly, the CAPM equation $E\left(r_{i, t}\right)=E\left(r_{f, t}\right)+\beta_{i}\left\{E\left(r_{m, t}\right)-E\left(r_{f, t}\right)\right\}$ captures the Market Risk Premium (MRP) or Equity Risk Premium, in the factor between brackets. MRP is typically positive as investors are rewarded for taking on systemic risk, however, as this paper will demonstrate that it can become negative with negatively correlated assets 
and markets.

Later in 1976, Stephen Ross proposed the Arbitrage Pricing Theory (APT) as an alternative for the CAPM model developed by Sharpe, Lintner and Treynor (ROSS, 1976). The APT suggests that the expected return of an asset or portfolio is the expected return on a risk free asset plus a proportional $\left(\beta_{i}\right)$ premium expected for exposure to certain macroeconomic factors, $\mathrm{E}(\mathrm{I})$. The equation $E\left(r_{i, t}\right)=E\left(r_{f, t}\right)+\beta_{i}\left\{E\left(I_{t}\right)-E\left(r_{f, t}\right)\right\}$ provided a coefficient beta indicating the exposure of asset/portfolio "i" to the factor "I".

A number of researchers observed empirical contradictions of the CAPM, as developed by Sharpe (1964), Linter (1965), Black (1972) and Treynor \& Black (1973). Banz (1981) showed a size effect, as he found that market equity enhances the explanation of average stock return variations provided by market Betas. Returns on low market equity stocks are too high given their Betas. Meanwhile, returns on high market equity stocks are too low. Another contradiction was discussed by Bhandari (1988) who found a positive relation between leverage and average returns. Leverage seems to contribute to the explanation of average stock return variations in models which included size as well as market beta.

Fama and French (1992) made some observations regarding bond and stock markets returns that would lead them to write their foundational paper in 1993 which identified two factors uniquely capable of explaining a larger part of excess returns in the stock market. The FFFM was an augmentation of the CAPM, an already widespread model in practice, and based on the theoretically sound Modern Portfolio Theory.

The FFFM is represented by the following equation:

$$
E\left(r_{i, t}\right)=E\left(r_{f, t}\right)+\beta_{1 i}\left\{E\left(r_{m, t}\right)-E\left(r_{f, t}\right)\right\}+\beta_{2 i} S M B_{t}+\beta_{3 i} H M L_{t}
$$

Where:

$r_{i, t}$ is the total return of a stock or portfolio, $i$ at time $t$;

$r_{f, t}$ is the risk free rate of return at time $\mathrm{t}$;

$r_{m, t}$ is the total market portfolio return at time $\mathrm{t}$;

$S M B_{t}$ is the size premium (small minus big);

$H M L_{t \mathrm{t}}$ is the value premium (high minus low);

$\beta_{1,2,3}$ refer to the factor coefficients.

We should note that in all models the asset returns and coefficients are asset/portfolio specific as denoted by subscript "i" whereas the factors are only time specific as denoted by subscript " $t$ ".

\section{Empirical Literature Review}

A number of researchers took it upon themselves to conduct empirical studies, in order to validate the FFFM in the context of national stock markets in various countries. The validity of this model was different from one country to another, but in contrast to the Fama-French experiment applied in US stock market, they were able to explain some of the variations in excess returns due to systemic risk exposure, size and $\mathrm{B} / \mathrm{M}$ valuation.

Using a quantitative methodology, Dolinar (2013) tested the FFFM on data taken from the Zagreb Stock Exchange (Croatia), for the period 2007-2013. He arranged 145 stocks in 4 portfolios depending on $\beta$, SMB, HML. A regression analysis was run per stock to see the significance of the factors on each stock. $\beta$ was significant for all stocks but SMB and HML and the factors were significant for some but not all stocks. This implies that the FFFM model captured additional variation missed by CAPM. The $\mathrm{R}^{2}$ per stock however, ranged from $30 \%$ to $75 \%$, which means that 30 to 75 percent of these variations were explained by the regressions run. Dolinar concluded that the model developed for the US stock can also be used to predict returns in other emerging markets.

Another FFFM application was done to test the validity of the model in the Turkish stock market (Veysel, 2013). The study was conducted for the period of 2003-2010 using monthly data in order to get more observations. Nine portfolios were constructed and a regression analysis was run. However, there was a different approach in explaining the result of the regression. What Veysel found, is that the P-values of the nine portfolios were close to zero and that constitutes a good fit. Yet, in order for the model to be valid, the value of the intercept should be different from zero. The regression showed intercept values different from zero for all nine portfolios. This means there is a certain amount of constant excess return unexplained by the model. The $\mathrm{R}^{2}$ for the 9 portfolios ranged from $67 \%$ to $94 \%$ which means there a good number of observations explained by the regression analysis. In conclusion, using the 
FFFM model, Veysel was able to explain more of the risk return tradeoff than using the CAPM.

Moreover, Esther and Ifuero conducted a study to investigate the validity of the FFFM model in the Nigerian stock market, as reported by Osamwanyi (2017). The test was done for the period of 2007-2014, where 139 stocks were used to construct 10 portfolios depending on size, return, beta and value in the analysis. The authors tested the three-factor model (FFFM) and the Carhart four-factor model and compared their results. They were able to explain average stock return variation better than the CAPM, and the Carhart model performed even better as it included momentum of stock as the fourth factor. The regressions run indicated that all intercept values were significant and different from zero, which means there remains constant excess returns in the Nigerian stock market during that period. The $\mathrm{R}^{2}$ for the 10 portfolios ranged from $21 \%$ to $86 \%$ which means that most of their observations were explained by the 4 four factor regressions.

A study conducted by Nayema and Peter examined the applicability of the FFFM model in the Kenyan stock market. In order to do the test, three empirical models were constructed, which were the standard three factor model, the three factor model adjusted for thin trading and an augmented three factor model (Achola \& Muriu, 2016). Nayema and Peter used daily stock prices for the period of July 2004 to June 2014 and the data was gathered from Nairobi Securities Exchange. Six portfolios were constructed depending on the intersection of book-to-market ratio and size. There was a positive relationship between the return of small size firms and the SMB factor and a negative relationship between the return of big size firms with the SMB factor. Similarly, for the HML factor, there was a positive relationship with high book value firms and negative relationship with low book value firms. The $\mathrm{R}^{2}$ values ranged from around $10 \%$ to $70 \%$ meaning that 10 to 70 percent of these variations were explained in the regressions. These three factors showed statistical significance in all the regressions that they did, which implies that the FFFM three factor model can be applicable in the Kenyan stock market.

\section{Methodology}

In order to test the Fama French Three Factor Model in Lebanon, some data manipulation is needed to arrive at the data set used in the regression models recommended by Fama and French. In the case of the Lebanese stock market, factors need to be constructed based on raw market data. The local stock market is characterized by 10 distinct issuers, an average daily volume of 337,000\$/day between 2011 and 2018, and an average market capitalization of $\$ 11.2$ billion between 2014 and 2018. The issuers are classified as follows:

development and reconstruction: Solidere,

financial: Bank Audi; BLC Bank; Bank of Beirut; Byblos Bank; Banque BEMO; BLOM Bank, trading: Rasmny Younis Motor Co.,

Industrial: Holcim Liban; Societe Libanaise des Ciments Blancs.

Data collection was possible using BLOM Bank's "Brite", a data bank specializing in Lebanese economic and financial indicators. Most of the issuers have common stock and preferred shares, and 3 of the 10 have Global Depositary Receipts (GDR). In line with the methodology of Fama and French (1993), only common shares and their respective book and market values are under consideration for our model. These data will be used for portfolio construction that reflect the underlying factors in question. These portfolios are then used to derive the factors to be used in regression analysis and quantify asset exposure to the factors.

\section{Primary Data}

\subsection{Common Stock Prices}

Daily stock prices were collected starting in 2011 up to the end of 2018 for all common stocks. Note that Solidere has two classes of common shares, A and B, respectively representing shares disbursed in kind for property acquisition, and cash subscription. Prices for A and B were averaged to obtain returns; this was done considering that price correlation is almost 1 (0.99896). Daily stock prices were used to obtain logarithmic annual stock returns using opening price at the beginning of the year and closing price at the end of the year. Annual returns will be used to derive portfolio returns in the portfolio construction process. Returns do not include dividends in order to remain consistent with the original Fama French methodology, the argument being that price returns and highly correlated with total returns and hence when using them in a regression model the desired variability is picked up.

\subsection{Risk Free Rates}

The benchmark for measuring the risk-free rate is the 1-year US Treasury bill obtained from FRED. The daily values are annualized by averaging the returns to obtain an annual benchmark denoted as "RF". 


\subsection{Book Value of Common Equity}

Total book value of common equity is obtained by adding book value of common equity, which measures par value of common shares multiplied by number of shares outstanding, to additional paid in capital or share premium, which is the price paid above par at a primary or seasoned offering.

\subsection{Market Value of Common Equity}

Ideally, market value of common equity is the average number of shares throughout the year multiplied by the average common share price of that same year. This could be obtained by using each company's respective annual statement. But for convenience, book value of common equity (already in time series format from BRITE) divided by par value per share (obtained from Beirut Stock Exchange) results in the number of common shares outstanding. This number multiplied by the stock price at year end results in the market value of the company at year end. If some inconsistencies arose, the number of shares from financial statements would be used to resolve the conflict. Conflicts may arise when there would be a significant change in equity position throughout the year.

\section{Portfolio Construction}

The portfolios constructed are attempts to build "pure" portfolios that reflect only one of the underlying factors in question. They are used to derive the factors to be used in regression analysis and quantify asset exposure to the factor. As prescribed by the FFFM (1993) methodology, an annual sort on market value of common equity segregated by annual median values. This generates two classifications: Small and Big. The labels are defined by the lagged market values. In other words, a small company in 2012, has a market value below the median in 2011. Considering that our data starts in 2011, there are no portfolios generated in 2011. The second sort is on lagged book to market values generated by dividing book values of common equity by market value of common equity. The sort is then segregated by 30th and 70th percentiles. Stocks that are above the 70th percentile are firms that have book values near market values and are labeled as value firms. Firms below the 30th percentile are labeled as growth firms, and in between the 30th and 70th percentile are neutral firms. The result is that in the 7 years of the study, excluding 2011, over 10 individual public companies, the sort generated the following distribution of labels.

Table 1. Distribution of labels

\begin{tabular}{ccccc}
\hline & Growth & Neutral & Value & Total \\
\hline Small & 13 & 15 & 7 & 35 \\
Big & 8 & 13 & 14 & 35 \\
Total & 21 & 28 & 21 & 70 \\
\hline
\end{tabular}

The portfolios can now be constructed based on the labels generated from the sorts by size and value. The original methodology dictates constructing market value weighted portfolios. This requires that each security within each respective portfolio be added based on the percentage of its market value on the total market value of the portfolio in question. Seven such portfolios are constructed including the general market portfolio used to calculate the market risk premium and the six portfolios generated by the sorts. The weights are used to derive the weighted returns of each portfolio, including the market portfolio is a value weighted portfolio including all stocks.

Table 2. Distribution of portfolios

\begin{tabular}{llll}
\hline Group & Mean & Standard Deviation & Frequency \\
\hline Small-Growth & $-0.9472 \%$ & $1.6323 \%$ & 7 \\
Small-Neutral & $-0.1102 \%$ & $1.4918 \%$ & 7 \\
Small-Value & $-1.4033 \%$ & $2.9877 \%$ & 7 \\
Big-Growth & $-0.9926 \%$ & $2.4557 \%$ & 7 \\
Big-Neutral & $-0.1499 \%$ & $1.2290 \%$ & 7 \\
Big-Value & $-1.1802 \%$ & $1.0939 \%$ & 7 \\
\hline Total & $\mathbf{- 0 . 7 9 7 2 \%}$ & $\mathbf{1 . 8 8 4 3 \%}$ & $\mathbf{4 2}$ \\
\hline
\end{tabular}




\section{Factor Construction}

For every year, Small minus Big (SMB) is the average value weighted return of each big portfolio subtracted from the value weighted returns of the small portfolios. In other words, the equal weighted average of the three small value weighted portfolios in year " $\mathrm{t}$ " minus the equal weighted portfolio of the three big value weighted portfolios in year " $\mathrm{t}$ ".

The same concept applies for the construction of the book-to-market sorts. The equal weighted average of the two high (value) portfolios in year " $t$ " minus the equal weighted average of the two low (growth) portfolios in year " $t$ ".

The traditional market risk premium is calculated on an annual basis taking the value weighted return on the market portfolio including all listed securities on the Beirut Stock Exchange minus the average annual return on US 1-year treasury bill.

Table 3. Annual factors

\begin{tabular}{llll}
\hline Year & MRP & SMB & $H M L$ \\
\hline 2012 & $-4.05 \%$ & $-0.90 \%$ & $0.89 \%$ \\
2013 & $-4.09 \%$ & $0.79 \%$ & $-1.03 \%$ \\
2014 & $-3.34 \%$ & $-0.49 \%$ & $-0.78 \%$ \\
2015 & $-0.75 \%$ & $0.20 \%$ & $-0.61 \%$ \\
2016 & $3.66 \%$ & $-4.80 \%$ & $-2.68 \%$ \\
2017 & $-10.22 \%$ & $0.93 \%$ & $-0.30 \%$ \\
2018 & $-18.30 \%$ & $3.95 \%$ & $2.26 \%$ \\
\hline average & $-5.30 \%$ & $-0.05 \%$ & $-0.32 \%$ \\
\hline
\end{tabular}

The table above summarizes the annual factors that result from the Fama French 1993 methodology. Because the results seem counter to the results of the original paper, we look to the Fama French factors posted on their website to ensure consistency with the methodology to explain why our size factors on average favor big companies and valuation factors on average favor growth firms. The FFF during the period of study demonstrate similar patterns at the annual and global level, as can be seen from the table below. We must note that both the SMB and HML factors are negative. Unlike the Fama French Global Factors, the Lebanese factors suggest that valuation factors are of a higher magnitude than size factors.

The market risk premium is negative which could potentially preclude it from the regressions in the subsequent sections. However, it is possible to interpret a negative risk premium as a market risk discount within the context of the regressions and not necessarily within the CAPM framework. The latter requires a positive risk premium that rewards investors for taking on systemic risk (beta). Because the beta remains a measure of systemic risk measuring $\frac{\operatorname{cov}\left(R M, R_{i}\right)}{\operatorname{Var}(R M)}$ then necessarily the market risk discount is punishing systemic risk taking.

Table 4. Annual factors: January-December Fama French Global

\begin{tabular}{lllll}
\hline & Mkt-RF & $S M B$ & $H M L$ & $R F$ \\
\hline 2012 & $16.88 \%$ & $-2.97 \%$ & $6.29 \%$ & $0.06 \%$ \\
2013 & $28.67 \%$ & $1.58 \%$ & $2.00 \%$ & $0.02 \%$ \\
2014 & $3.28 \%$ & $-5.62 \%$ & $-2.90 \%$ & $0.02 \%$ \\
2015 & $-0.37 \%$ & $3.49 \%$ & $-9.47 \%$ & $0.02 \%$ \\
2016 & $7.90 \%$ & $2.63 \%$ & $15.48 \%$ & $0.20 \%$ \\
2017 & $23.51 \%$ & $2.82 \%$ & $-7.50 \%$ & $0.80 \%$ \\
2018 & $-11.40 \%$ & $-6.37 \%$ & $-7.26 \%$ & $1.81 \%$ \\
\hline average & $9.78 \%$ & $-0.63 \%$ & $-0.48 \%$ & $0.42 \%$ \\
\hline
\end{tabular}




\section{Interpretation and Analysis}

Since the seminal work of Fama and French in 1993, the risk factor exposure to size and value have inverted. This can be noted in the table obtained from Fama and French's website, summarizing global factors over the same time period. Both size and value now demonstrate negative coefficients, suggesting that the outperformance of small firms has vanished. Moreover, value firms are now outperformed by growth firms.

Knowing that the factors are sensitive to the time period chosen, we note that the results are consistent with Fama French's updated data. It is also worth noting that the value factor, HML, is of a similar magnitude to the global Fama French Factor. Similarities stop here.

The size factor in Lebanon appears insignificantly small, averaging $-0.05 \%$ over the time period. Most concerning is the negative market risk premium displayed in Lebanon. This could be partly explained by three potential reasons. First, Lebanon's public equity market demonstrates a negative correlation with US treasury returns. Second, adding to negative correlation, the time period under study was characterized by a strong bull market in the US and weak economic growth in Lebanon. Third, Lebanese public companies transfer most of their returns through dividend yields offsetting capital gains. Because the Fama French model prescribes using only capital gain returns and not total returns, the model may be inappropriate without modification in modelling market risk premiums used in FFFM and CAPM.

Further suspicion arises when correlations between the three factors are taken into consideration. The Lebanese factors demonstrate extremely high correlations placing doubt in the applicability of the traditional least squares regression used in the original methodology. This problem does not appear to be significant in the FFFM original paper and updated data (table below).

Table 5. Correlation Matrix Lebanese factors

\begin{tabular}{llll}
\hline & MRP & SMB & HML \\
\hline MRP & 1.0000 & & \\
SMB & -0.8901 & 1.0000 & \\
$H M L$ & -0.8529 & 0.8202 & 1.0000 \\
\hline
\end{tabular}

Table 6. Correlation Matrix global factors

\begin{tabular}{llll}
\hline & $M R P$ & $S M B$ & $H M L$ \\
\hline$M R P$ & 1.0000 & & \\
$S M B$ & 0.4981 & 1.0000 & \\
$H M L$ & 0.2870 & 0.1369 & 1.0000 \\
\hline
\end{tabular}

\section{Conclusions}

Stock return, be it capital gain or dividend or both, may vary from one stock to another, or one portfolio to another, or even one market to another, due to a number of reasons. Market risk in particular, became a cornerstone in optimizing investment strategies ever since the development of the CAPM model. Yet the latter proved to have a number of important shortcomings, as it was shown in a number of studies and research projects.

Research work done by Fama and French in the early 1990's concluded that size and valuation, in addition to market risk, are significant in contributing to the explanation of average stock return variations. Consequently, a number of empirical studies were conducted in various stock markets to test and validate the FFFM model. In general, the results support the significance of size and valuation.

Our research on the validity of the FFFM model, as it applies to the small Lebanese stock market yielded mixed results. First, market risk, size and valuation are significant in explaining average stock market variations in Lebanon, just like they are in global equity markets. However, the size factor in Lebanon appears to be insignificantly small, averaging $-0.05 \%$ over the time period. Second, the Lebanese stock market exhibited negative market risk premium over the time period in question. This may be due to the apparent empirical phenomena of counter-cyclicality between the US and the Lebanese economies. Third, there is a high degree of correlation among the three factors in 
the Lebanese stock market.

In the final analysis, the FFFM model seem to be valid and it does represent explanatory improvement over the conventional CAPM model. However, its application in the Lebanese stock market will necessitate some modifications and adaptation.

\section{References}

Achola, N. K., \& Muriu, P. (2016). Testing The Three Factor Model Of Fama And French: Evidence From An Emerging Market. European Scientific Journal, 12, 211-236. https://doi.org/10.19044/esj.2016.v12n16p211

Banz, R. W. (1981). The Relationship Between Return and Market Value of Common Stocks. Journal of Financial Economics, 9(1), 3-18. https://doi.org/10.1016/0304-405X(81)90018-0

Bhandari, L. C. (1988). Debt/Equity Ratio and Expected Common Stock Returns: Empirical Evidence. Journal of Finance, 43(2), 507-28. https://doi.org/10.1111/j.1540-6261.1988.tb03952.x

Black, F. (1972). Capital Market Equilibrium with Restricted Borrowing. Journal of Business. 45(3), 444-54. https://doi.org/10.1086/295472

Carhart, M. M. (1997). On Persistence in Mutual Fund Performance. The Journal of Finance, 52(1), 57-82. https://doi.org/10.1111/j.1540-6261.1997.tb03808.x

Dolinar, D. (2013). Test of The Fama-French Three-Factor Model in Croatia. UTMS Journal of Economics, $101-112$.

Esther, I. E-O., \& Ifuero, O. O. (2017, October). A Comparative Analysis of Four-Factor Model and Three-Factor Model in the Nigerian Stock Market. Journal of Financial Research, Sciedu Press, 8(4), 38-52. https://doi.org/10.5430/ijfr.v8n4p38

Fama, E. F., \& French, K. R. (2004). The Capital Asset Pricing Model: Theory and Evidence. The Journal of Economic Perspectives, 25-46. https://doi.org/10.1257/0895330042162430

Lintner, J. (1965). The Valuation of Risk Assets and the Selection of Risky Investments in Stock Portfolios and Capital Budgets. Review of Economics and Statistics, 47(1), 13-37. https://doi.org/10.2307/1924119

Markowitz, H. (1952, March). Portfolio Selection. The Journal of Finance, 7, 77-91. https://doi.org/10.1111/j.1540-6261.1952.tb01525.x

Osamwonyi, E. I.-O. (2017). A Comparative Analysis of Four-Factor Model and Three-Factor Model in the Nigerian Stock Market. International Journal of Financial Research, 8, 38-53. https://doi.org/10.5430/ijfr.v8n4p38

Ross, S. A. (1976). The Arbitrage Theory of Capital Asset Pricing. Journal of Economic Theory, 341-360. https://doi.org/10.1016/0022-0531(76)90046-6

Sharpe, W. F. (1964). Capital Asset Prices: A Theory of Market Equilibrium under Conditions of Risk. The Journal of Finance, 19, 425-442. https://doi.org/10.1111/j.1540-6261.1964.tb02865.x

Treynor, J. L., \& Black, F. (1973). How to Use Security Analysis to Improve Portfolio Selection. The Journal of Business, 46(1), 66-88. https://doi.org/10.1086/295508

Veysel, E. (2013). Fama and French Three-Factor Model. Business and Economics Research, 4, 11-22.

\section{Copyrights}

Copyright for this article is retained by the author(s), with first publication rights granted to the journal.

This is an open-access article distributed under the terms and conditions of the Creative Commons Attribution license (http://creativecommons.org/licenses/by/4.0/). 